\title{
Hybrid PSO-GSA algorithm-based optimal control strategy for performance enhancement of a grid-connected wind generator
}

\author{
Mina N. Amin ${ }^{1}$, Mahmoud A. Soliman ${ }^{2}$, Hany M. Hasanien ${ }^{3}$, Almoataz Y. Abdelaziz ${ }^{4}$ \\ ${ }_{1,3,4}$ Electrical Power \& Machines Departement, Faculty of Engineering, Ain Shams University, Egypt \\ ${ }^{2}$ Dynamic Positioning and Navigation Department, Petroleum Marine Services Co., Alexandria, Egypt
}

\begin{tabular}{l} 
Article Info \\
\hline Article history: \\
Received Oct 11, 2019 \\
Revised Feb 19, 2020 \\
Accepted Mar 4, 2021 \\
\hline
\end{tabular}

Keywords:

Frequency converter HPSO-GSA

Renewable energy

Variable-speed wind turbine

\begin{abstract}
Due to the great level of wind energy penetration in the existing network, huge efforts have been directed to enhance the grid-connected wind generator performance. This paper shows an application of a hybrid algorithm of the particle swarm optimization and the gravitational search algorithm (PSO-GSA) to enhance the transient stability of the grid-tied wind energy conversion system. The variable-speed wind turbine (VSWT) directdrive permanent-magnet synchronous generator is connected to the network through a full-scale converter. The generator- and grid-side converters are controlled by utilizing an optimum proportional-integral (PI) controller. The criterion of the integral squared error is utilized as an objective function. The PSO-GSA based-PI controller efficacy is validated by comparing its results with that are obtained by utilizing the genetic algorithm (GA)-based-PI controller. The performance of the suggested control scheme is checked during various fault conditions. The control scheme quality is legalized by the simulation results that are obtained using MATLAB/Simulink program
\end{abstract}

This is an open access article under the CC BY-SA license.

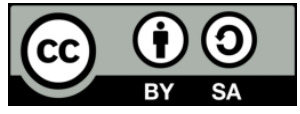

Corresponding Author:

Mina N. Amin

Department of Electrical Power \& Machines

Ain Shams University

1El-Sarayat Street, Abdo Basha Square, Cairo, Egypt

Email: mina_nabil@eng.asu.edu.eg

\section{INTRODUCTION}

Recently, massive attention has been directed to renewable energy around the globe, for various reasons, such as the cost growth of the traditional power generation, environmental needs, and probability of the demise of fuel. According to the latest statistics, it is expected that new installations of more than $55 \mathrm{GW}$ will be added in the grid each year until 2023 [1]. Based on the enormous level of wind energy participation in the existing electrical grid, some problems have arisen. Some of these problems are the fluctuations of the wind farms out put power and the low voltage through capability. So, the wind energy transient characteristics have to be studied.

The variable-speed wind generator system (VSWG) has many merits than that of the fixed in the wind energy conversion system (WECS). Some of these merits are the capability to capture maximum power and reducing the mechanical stress on the drive-train [2,3]. There are various types of electrical generator used in the VSWG, such as switched reluctance generator (SRG) [4], a doubly-fed induction generator (DFIG) [5, 6], and permanent magnet synchronous generator (PMSG) [7-13]. The PMSGs have many advantages, for example, they have high number of poles, therefore there are power can be achieved at low rotational speed and there is no needing for gearbox resulting in reducing cost.

The grid-tied variable-speed wind turbine (VSWT)-PMSG is composed of both full-scale frequency converters at the generator- and grid-side, intermediate capacitor (C), transformer as step-up, and two 
transmission lines. The vector control has utilized in controlling the generator- and grid-side converters. In this study, the vector control depends on the proportional-integral (PI) controller [14-17]. The proportionalderivative (PD) and proportional-integral-derivative (PID) controllers are not more attractive to be utilized in the industry due to the disadvantages of derivative control action, where it increase the input harmonics frequency to the system, and to prevent this problem, a designed filter should be utilized. Therefore, PI controller is commonly used in the industry. PI controllers have characterized by having a large stability limit, although they are affected by the variation of the parameters. Four PI are utilized for each converter, so the fine-tuning of these controllers is arduous, especially in the non-linear system.

Many approaches are utilized to reach the optimal parameters of the PI to increase the efficiency of the grid-VSWG. Traditionally, Newton-Raphson (NR) and Ziegler-Nichols (ZN) approaches are used to finetune the PI controller, but these optimizations methods are affected by the type of solver and the initial conditions. Besides, the heuristic approaches, such as the gravitational search algorithm (GSA), a genetic algorithm (GA), the particle swarm algorithm (PSO) [18], a grey wolf optimizer (GWO), and the ant colony optimization (ACO) are used to obtain the optimal values of the PI controllers. But these methods suffer from some drawbacks in finding the ideal solution. The GA technique can be applied for both continuous and discrete parameters, but it need a complex analysis, a long time, and can be trapped into local optima. The PSO has some advantages such as its simplisty and it has few parameters to adjust. But, PSO can have difficulty to get the initial design parameters, and it can converge early and can be trapped into local optimum solutions with complex problems. GSA depends on Newton's law of mass attraction and gravity. GSA has some merits, including the ability to solve highly nonlinear optimization problems and has stable convergence characteristics. But, GSA has drawbacks such as it has slow searching speed in the last iterations and has long computational time. ACO can give rapid discovery of reasonable solutions and has guaranteed convergence. But, ACO has an uncertain time to convergence and has a complicated theoretical analysis. The GWO has some demerits, such as need to long time in convergence and inadequate local searching ability.

The main characteristics of the optimization process are the balance between the exploration and the exploitation to reach to the optimal solution. This article presents the application of PSO-GSA [19-23] basedPI to control the frequency converter (FC). The PSO-GSA has many merits, such as better capability to escape from local optima solution and has a faster convergence rate. The performance of PSO-GSA is ensured by comparing the results are achieved by PSO-GSA based-PI controller with that obtained from the application of a GA-based PI controller. The various types of faults are considered in this comparison. These simulation results are performed by utilizing the MATLAB/Simulink programming.

\section{MODEL SYSTEM}

The main component to adjust output of the VSWT-PMSG is the FC, as shown in Figure 1. The FC is composed of two full-scale power converters at the generator and grid-side, $\mathrm{C}$. the capacitor is protected by an over-voltage protection scheme (OVPS) during the fault. Each vector control scheme has four PI controllers to control the generator and grid-side converters. The generator-side converter (GSC) is managed to obtain maximum power at power factor equal one, from the generator. The terminal voltage at the common coupling point $\left(V_{P C C}\right)$ and the DC voltage $\left(V_{D C}\right)$ are regulated by the grid-side inverter $(\mathrm{GSI})$. The interconnection between the output of the VSWT-PMSG is composed of transformer and double circuit transmission line. The data of PMSG are illustrated in Table 1.

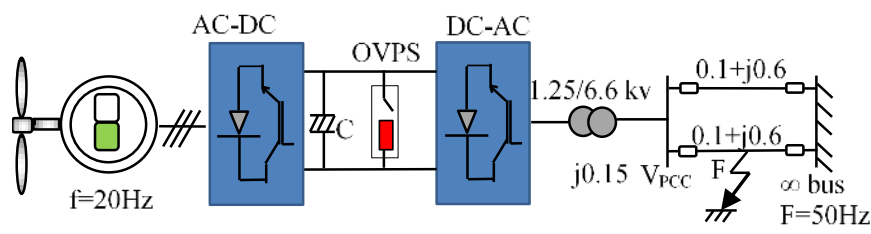

Figure 1. System model

Table 1. Generator parameters

\begin{tabular}{cccl}
\hline$P_{\text {rated }}$ & $V_{\text {rated }}$ & Frequency & No. poles \\
\hline $1.5 \mathrm{MW}$ & $575 \mathrm{~V}$ & $20 \mathrm{~Hz}$ & 48 \\
$R_{\text {stator }}$ & $X_{d}$ & $X_{q}$ & Field Flux \\
$0.006 \mathrm{pu}$ & $0.7 \mathrm{pu}$ & $0.3 \mathrm{pu}$ & $0.9 \mathrm{pu}$ \\
\hline
\end{tabular}




\section{WIND TURBINE MODEL}

The relation among the speed of the wind and mechanical power can be presented as follow [3]:

$$
P_{\omega}=0.5 \rho \pi R^{2} V_{\omega}^{3} C_{P}(\lambda, \beta)
$$

where $V_{\omega}$ is the speed of the wind, $\rho$ is the density of air, $R$ is the radius of the blade, $C_{P}$ presents the power coefficient, which depends on turbine pitch angle, $\beta$ and tip speed ratio, $\lambda$ and where $\omega_{r}$ means the rotational rotor speed it can be modeled as:

$$
\begin{aligned}
& \lambda=\frac{\omega_{r} R}{V_{\omega}} \\
& L_{i}=\frac{1}{\left(\frac{1}{\lambda+0.02 \beta}\right)-\left(\frac{0.03}{\beta^{3}+1}\right)} \\
& C_{P}(\lambda, \beta)=0.73\left(\left(\frac{151}{L i}\right)-0.58 \beta-0.002\left(\beta^{2.14}\right)-13.2\right) e^{-18.4 / L_{i}}
\end{aligned}
$$

VSWT is preferred over the FSWT in WECS due to it able to amplify the extracted power at the wind speed variations. Figure 2 exhibits turbine characteristic. It is noted that there are different curves for the extracted power at various wind speeds. For each curve, a specific point where the maximum power can be captured. So, the adjustable controller has to follow the particular rotational speed to get the maximum power at each wind speed. This scheme is known as maximum power point tracking (MPPT)

To get $P_{\max }$ in terms of $\omega_{r}$ utilize this equation [3]:

$$
P_{\text {max }}=0.5 \rho \pi R^{2}\left(\frac{\omega_{r} R}{\lambda_{o p t}}\right)^{3} C_{P-o p t}
$$

where $C_{p-o p t}$ is coefficient of optimum power and $\lambda_{\text {opt }}$ is optimum value of the tip speed ratio. The rated power will be otherwise called $P_{\text {opt }}$ which is used as the adjusting point for the power at FC.

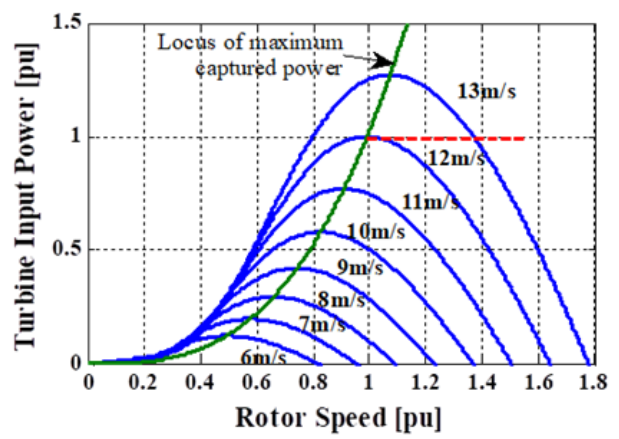

Figure 2. Wind turbine characteristic with MPPT curve

\section{THE FC CONTROL}

The controlling the behavior of the grid-connected VSWT-PMSG is based on the FC, to extract $P_{\text {max }}$ from the generator and adjusting the $V_{P C C}, V_{D C}$ at various operating conditions. It composes of the GSI, $\mathrm{GSC}$, and $\mathrm{C}$.

\subsection{GSC}

The GSC has the major rule to deliver $P_{\max }$ from the generator at power factor equal one. This output is obtained by adjusting the $d q$-axes components of the stator current $\left(I_{d}, I_{q}\right)$. The $P_{\max }$ from the generator is achieved by adjusting the $I_{q}$ according to the set-point $\left(P_{\text {opt }}\right)$, which is obtained from MPPT. The $I_{d}$ is adapted to deliver the power when the power factor equal one. As illustrated in Figure 3, there are four PI-controllers to control the GSC to acheive the $d q$-axes components of the reference voltage $\left(V^{*}{ }_{d, q}\right)$. These components are transformed into three-phase components $\left(V^{*}{ }_{a, b, c}\right)$. A comparison is occurred between $V^{*}{ }_{a, b, c}$ and a $1 \mathrm{kHz}$ triangular carrier waveform (TCW), to get firing pulses (FP) for the converter. 

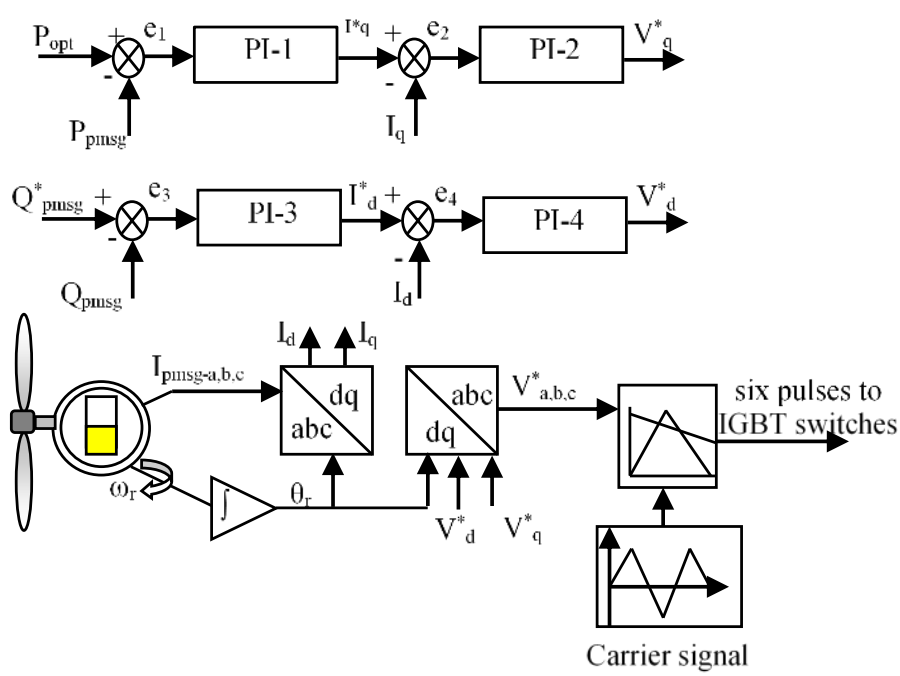

Figure 3. The generator-side converter control block diagram.

\subsection{GSI}

The GSI has the responsibility to control $V_{D C}$ and $V_{P C C}$ by adjusting the $d$-axis and $q$-axis grid current components $\left(I_{d n}, I_{q n}\right)$. The $I_{q n}$ is adjusted to control of the $V_{D C}$, and the $I_{d n}$ is adjusted to maintain the $V_{P C C}$ to be stable at sever disturbances. In this analysis, the $\mathrm{C}$ is selected as $10 \mathrm{mF}$ with a rated voltage with rated value equal to $1.15 \mathrm{kV}$. As obtaned in Figure 4, the grid side inverter control block diagram, to extract the reference voltage $\left(V_{d n, q n}^{*}\right)$ by utilizing four PI-controllers. The $V_{d n, q n}^{*}$ are transformed into three-phase signals $V^{*}{ }_{a n, b n, c n}$ by utilizing a transformation angle $\left(\theta_{t}\right)$. A comparison is occurred between $V^{*}{ }_{a n, b n, c n}$ with a TCW with $1050 \mathrm{~Hz}$ to produce FP to the GSI. To extract $\left(\theta_{t}\right)$, a phase-locked-loop (PLL) is utilized.

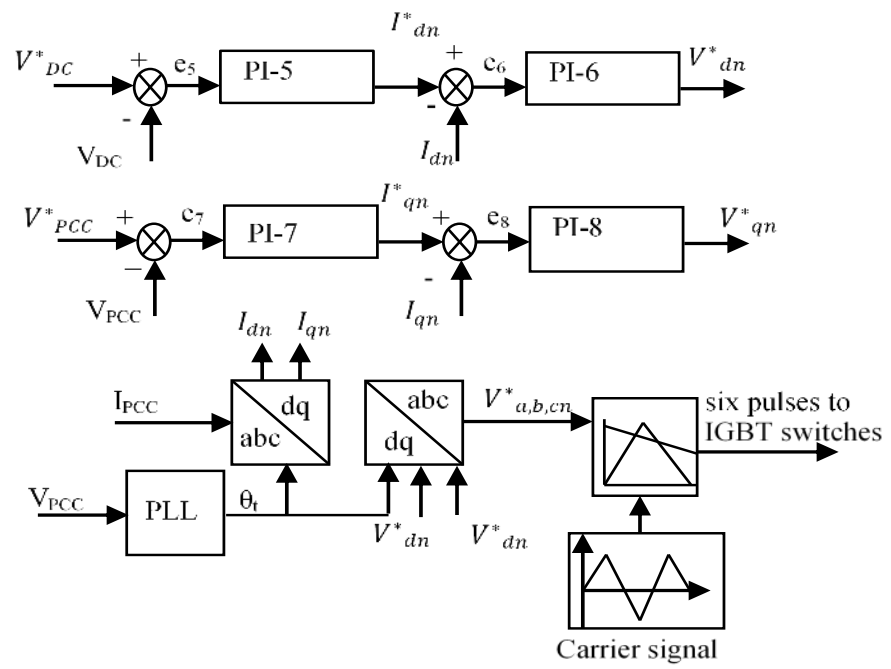

Figure 4. The grid-side inverter control block diagram

\subsection{OVPS}

During the fault condition, the reactive power $\left(Q_{r}\right)$ is delivered to the grid. At the same time, no real power $\left(P_{r}\right)$ is transmitted to the network, which results in increasing the $V_{D C}$ and leading to destroy the $\mathrm{C}$. The OVPS is needed to protect the $\mathrm{C}$ from damaging. The components of the OVPS are the controlled IGBT with series in resistance [24]. When $V_{D C}$ exceeds $20 \%$ above the nominal value of the $V_{D C}$, IGBT will operate to dissipate the power through the resistance. So, OVPS will prevent the damaging of the intermediate C. 


\section{HYBRID PSO-GSA AND PROBLEM FORMULATION}

This optimization method is the merging of two algorithms GSA and PSO. The combination of the GSA and PSO is performed by utilizing the low-level co-evolutionary heterogeneous hybrid. PSO-GSA is defined as co-evolutionary as it runs the two algorithms in parallel combination. The development of the PSO-GSA depends on the capability of the PSO for Social thinking and GSA ability to get the local search. The merging can be mathematically modeled as follow:

$$
V_{I}(t+1)=w * V_{i}(t)+c_{i} * \operatorname{rand} * a c_{i}(t)+c_{2}(t) * \operatorname{rand} *\left(g_{\text {best }}-X_{i}(t)\right)
$$

where $V_{i}(t)$ shows the $i$ agent velocity at $t$ iteration, $a c_{i}(t)$ is the agent $i$ acceleration at iteration $t, c_{j}$ is a weighting factor, $w$ is a weighting function, $g_{b e s t}$ is the best solution so far. At each iteration end, the particle velocity and position are updated as follow:

$$
X_{i}(t+1)=X_{i}(t)+V_{i}(t+1)
$$

For the PSO-GSA process, firstly there is initialization for all agents randomly. Then for all agents, the resultant force among each other, gravitational constant, and gravitational force are calculated. After this phase, the GSA is utilized to get the acceleration of the particles. The best solution has updated at the end of each iteration. Then by utilizing the equations $(6,7)$, for all agents, the velocity and the position can be calculated. The updating process can be finished, when the criteria of the velocity and the position reach the end. The search space is explored by the agents are founded close to the real best solution; they attract other agents. The exploiting of the global best depends on the agents are near to the best solution and move very slowly. The $\mathrm{c} 1$ and $\mathrm{c} 2$ are regulated to obtain the equilibrium among the local search and the global search. Figure 5 shows the flowchart of GSA. Figure 6 presents the steps of PSO. Figure 7 presents the flowchart of PSO-GSA.

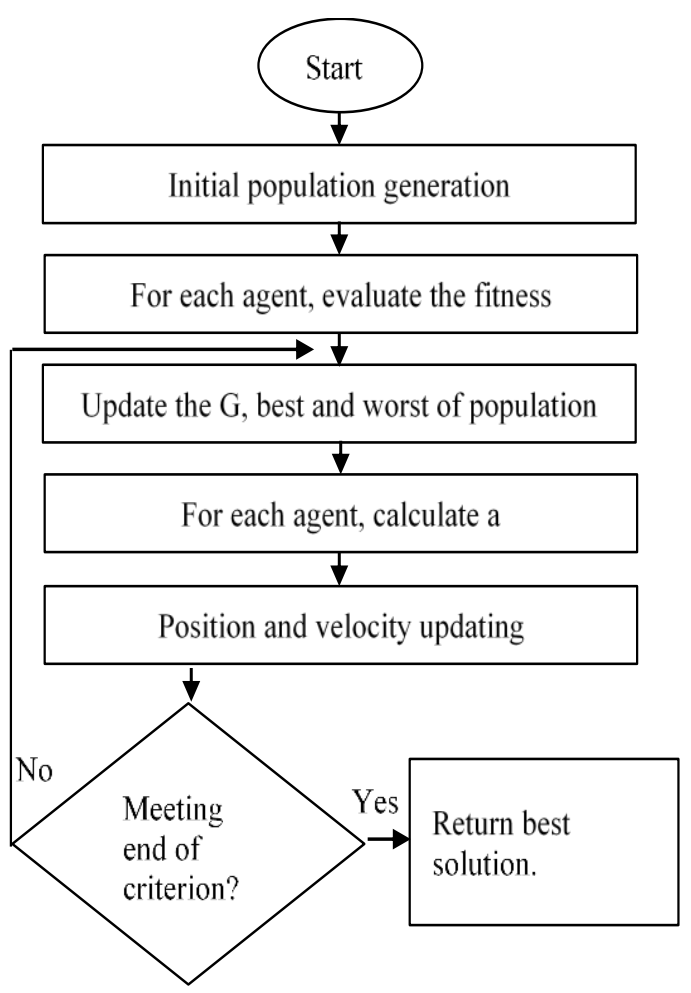

Figure 5. Flow chart of gravitational search algorithm

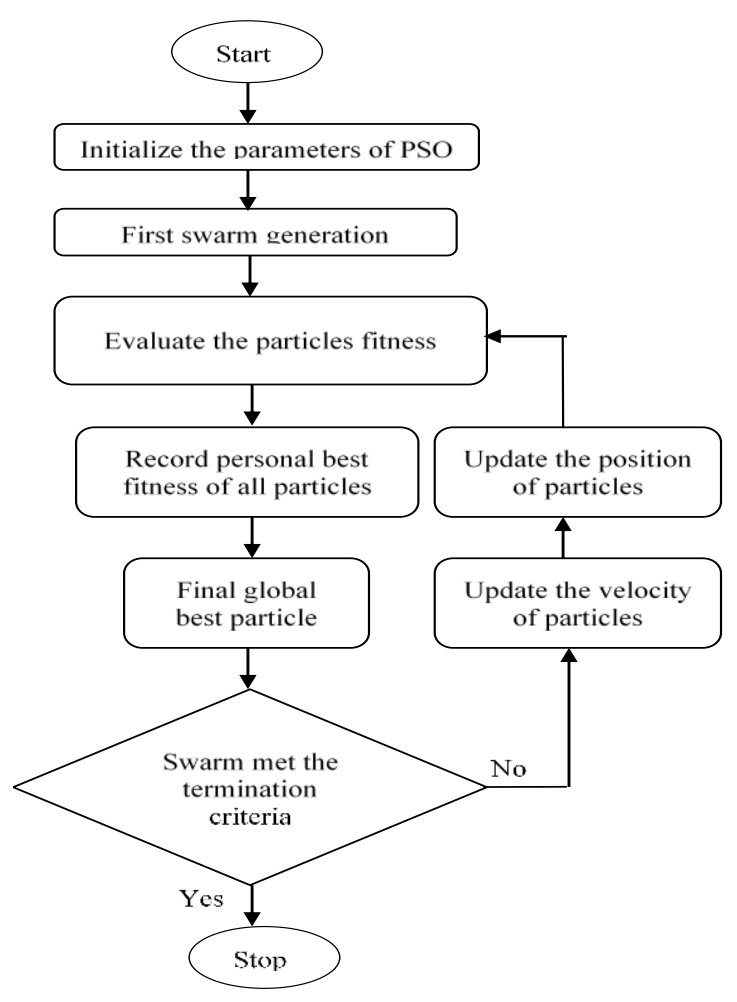

Figure 6. Flow chart of particle swarm optimization 


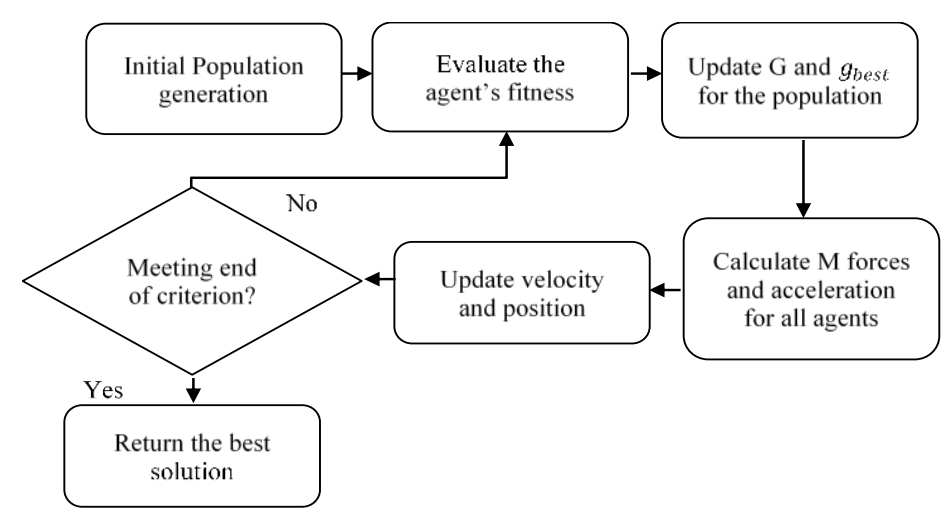

Figure 7. The hybrid PSO-GSA algorithm flow chart

Choosing of the objective function in our problem is done by using integral square error (ISE) criterion, as expressed:

$$
I S E=\int_{0}^{t}\left(\left(e_{1}{ }^{2}+e_{2}{ }^{2}+e_{3}{ }^{2}+e_{4}{ }^{2}\right)+\left(e_{5}{ }^{2}+e_{6}{ }^{2}+e_{7}{ }^{2}+e_{8}{ }^{2}\right)\right) \cdot d t
$$

where $e_{1}, e_{2}, e_{3}$, and $e_{4}$ are the actuating errors of $P_{o p t}, I_{q}, Q_{p m s g}$, and $I_{d}$, respectively, for generator-side and $e_{5}, e_{6}, e_{7}$, and $e_{8}$ are the actuating errors of $V_{D C}, I_{d n}, V_{P C C}$, and $I_{q n}$, respectively, for the grid-side.

\section{SIMULATION RESULTS}

The simulation results are achieved by using the MATLAB/Simulink program. The simulation time step is 5 micro sec. The results of the PSO-GSA based-PI are compared with that are produced by the GA-PI to confirm the PSO-GSA based-PI efficacy under the various disturbances. The three-line to ground fault (3LG) is occurred at $1.7 \mathrm{sec}$ at point $\mathrm{F}$, as shown in Figure 1. At $1.8 \mathrm{sec}$, the circuit breaker at the faulted line is opened and then reclosed at $2.1 \mathrm{sec}$ after clearing the fault. Figure 8 (a) represent the response of the $P_{r}$ utilizing PSO-GSA-PI controller is faster and better damped than that achieved by GA-PI. Figure 8 (b) illustrates the response of $Q_{r}$. It is noticed that the response of $Q_{r}$ by PSO-GSA based-PI has lower settling time than that is achieved by GA-based-PI. Figure 8 (c) illustrates the $V_{D C}$. Notably, $V_{D C}$ has lower overshoot and better-damped response by utilizing PSO-GSA based-PI than that is obtained by utilizing the GA-PI. Figure 8 (d) presents the $V_{P C C}$ response. Notably, at the steady-state, the response of $V_{P C C}$ using PSO-GSA based-PI has low settling time and has a small error than that obtained by utilizing GA-PI.

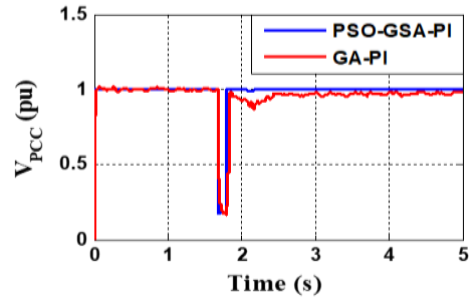

(a)

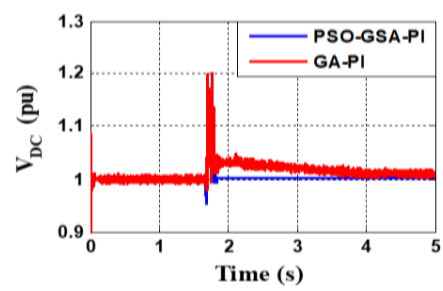

(c)

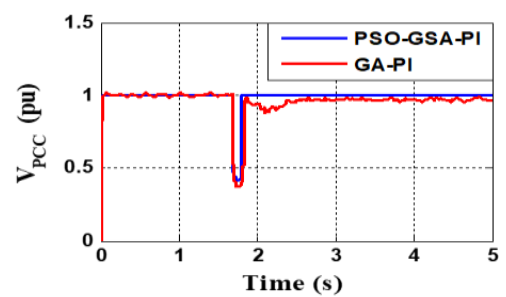

(b)

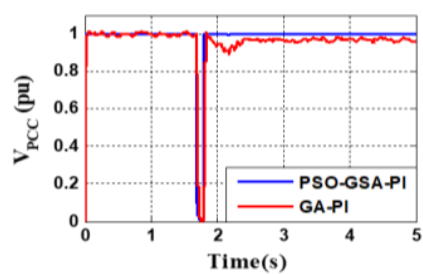

(d)

Figure 8. 3LG temporary fault responses (a) $P_{r}$. (b) $Q_{r}$. (c) $V_{D C}$. (d) $V_{P C C}$ 
For further proof of the PSO-GSA based-PI controller efficiency, the system is subjected to unsymmetrical faults. Single line-to-ground fault (1LG), the line-to-line fault (LL), and double line-to-ground fault (LLG). Figure 9 shows the responses of the $V_{P C C}$ according to unsymmetrical faults. Figure 9(a) illustrates the $V_{P C C}$ at the LLG fault. Figure 9 (b) shows the $V_{P C C}$ at the LL fault. Figure 9 (c) shows the $V_{P C C}$ at the 1LG fault. Finally, the PSO-GSA based-PI can improve the transient stability of VSWT-PMSG under various disturbances.

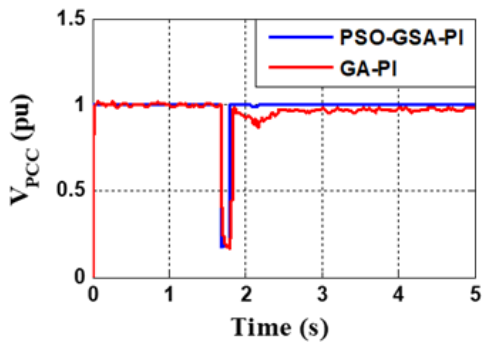

(a)



(b)

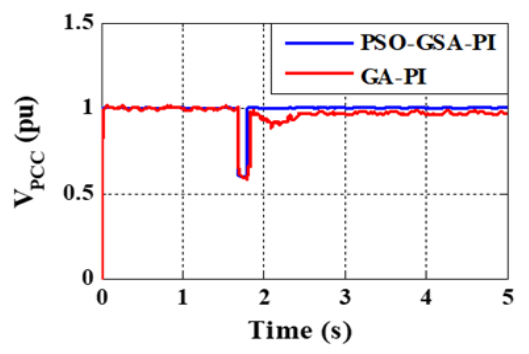

(c)

Figure 9. Responses of $V_{P C C}$ under the unsymmetrical faults, (a) LLG, (b) LL, (c) 1LG

\section{CONCLUSION}

This article has illustrated an implementation of the PSO-GSA based-PI to improve the behavior of the grid-tied VSWT-PMSG. The PSO-GSA based-PI is legalized by comparing its results with that are achieved by utilizing GA based-PI controller. The suggested strategy is utilized in controlling the FC to deliver and smooth the $P_{r}$, and to adjust the terminal voltage to be constant at various operating conditions. It is clear from the simulation results that the transient system responses using PSO-GSA based-PI controller have better-damped responses and minimum oscillations than that are obtained using GA-based PI. The efficiency of the PSO-GSA based PI is checked under various fault conditions. Finally, the PSO-GSA basedPI controller has efficiency to deal with controlling the non-linear system. Therefore, the proposed control scheme can be used to achieve enhanced response in other systems, smart grids, and storage energy systems.

\section{REFERENCES}

[1] Global Wind Energy Council (GWEC), "Global Wind Energy Outlook," 2017. [Online]. Available: http://www.gwec.net.

[2] M. A. Soliman, H. M. Hasanien, H. Z. Azazi, E. E. El-kholy and S. A. Mahmoud, "Hybrid ANFIS-GA-based control scheme for performance enhancement of a grid-connected wind generator," IET Renew. Power Gener., vol. 12, no. 7, pp. 832-843, 2018.

[3] H. M. Hasanien and S. M. Muyeen, "Affine projection algorithm based adaptive control scheme for operation of variable-speed wind generator," IET Gener., Trans. \& Distrib., vol. 9, no. 16, pp. 2611-2616, 2015.

[4] H. M. Hasanien and S. M. Muyeen, "Speed control of grid-connected switched reluctance generator driven by variable speed wind turbine using adaptive neural network controller," Electr. Power Syst., vol. 84, no. 1, pp. 206$213,2012$.

[5] H. M. Hasanien and E. A. Al-Ammar "Dynamic response improvement of doubly fed induction generator-based wind farm using fuzzy logic controller," J. Electr. Eng., vol. 63, no. 5, pp. 281-288, 2012.

[6] S. Hassan, B. Abdelmajid, Z. Mourad, S. Aicha and B. Abdenaceur, "PSO-backstepping controller of a grid connected DFIG based wind turbine," International Journal of Electrical and Computer Engineering (IJECE), vol. 10, no. 1, pp. 856-867, Feb. 2020. 
[7] M. N. Amin, M. A. Soliman, H. M. Hasanien and A. Y. Abdelaziz, "Grasshopper optimization algorithm-based pi controller scheme for performance enhancement of a grid-connected wind generator," J Control Autom Electr Syst, vol. 31, pp. 393-401, 2020.

[8] M. N. Amin, M. A. Soliman, H. M. Hasanien, A. Y. Abdelaziz and Z. Ali, "Grasshopper optimization algorithmbased fuzzy logic controller for performance enhancement of a grid-connected wind generator," International Journal on Energy Conversion (IRECON), vol. 7, no. 6, pp. 218-229, 2019.

[9] Venkatachalam K. M. and V. Saravanan, "Grid integration of PMSG based wind energy conversion with battery storage system," International Journal of Applied Power Engineering (IJAPE), vol. 10, no. 1, pp. 48-57, Mar. 2021.

[10] A. M. Kassem, "Modelling and robust control design of a standalone wind-based energy storage generation unit powering an induction motor-variable-displacement pressure-compensated pump," IET Renewable Power Generation, vol. 10, no. 3, pp. 275-286, 2016.

[11] M. H. Qais, H. M. Hasanien, and S. Alghuwainem, "A grey wolf optimizer for optimum parameters of multiple PI controllers of a grid-connected PMSG driven by variable speed wind turbine," IEEE Access, vol. 6, pp. 4412044128, 2018.

[12] M. A. Soliman, H. M. Hasanien, H. Z. Azazi, E. E. El-Kholy, and S. A. Mahmoud, "An adaptive fuzzy logic control strategy for performance enhancement of a grid-connected PMSG-based wind turbine," IEEE Trans. on Ind. Infor., vol. 15, no. 6, pp. 3163-3173, Jun. 2019.

[13] M. H. Qais, H. M. Hasanien and S. Alghuwainem, "Low voltage ride-through capability enhancement of gridconnected permanent magnet synchronous generator driven directly by variable speed wind turbine: a review," The Journal of Engineering, vol. 2017, no. 13, pp. 1750-1754, 2017.

[14] M. H. Qais, H. M. Hasanien and S. Alghuwainem, "Output power smoothing of grid-connected permanent-magnet synchronous generator driven directly by variable speed wind turbine: a review," The Journal of Engineering, vol. 2017, no. 13, pp. 1755-1759, 2017.

[15] M. H. Qais, H. M. Hasanien and S. Alghuwainem, "Enhance salp swarm algorithm: application to variable speed wind generators," Engineering Appl. of Artificial Intelligence, vol. 80, pp. 82-96, 2019.

[16] Nityanand and A. K. Pandey, "Performance analysis of PMSG wind turbine at variable wind speed," 2018 5th IEEE Uttar Pradesh Section International Conference on Electrical, Electronics and Computer Engineering (UPCON), Gorakhpur, 2018, pp. 1-6.

[17] R. A. Gupta, B. Singh and B. B. Jain, "Wind energy conversion system using PMSG," 2015 International Conference on Recent Developments in Control, Automation and Power Engineering (RDCAPE), 2015, pp. 199203.

[18] H. M. Hasanien and S. M. Muyeen, "Particle swarm optimization-based superconducting magnetic energy storage for low-voltage ride-throughcapability enhancement in wind energy conversion system," Electr. Power Compon. Syst., vol. 43, no. 11, pp. 1278-1288, 2015.

[19] D. M. Mustafa, K. H. Youssef, I. F. Elarabawy and T. H. Abdelhamid, "Hybrid particle swarm optimization and gravitational search algorithm for BLDC motor speed control," 2018 Twentieth International Middle East Power Systems Conference (MEPCON), 2018, pp. 1140-1147.

[20] M. Saleh, F. Imansyah, U. A. Gani and H., "Hybrid PSO-GSA technique for environmental/ economic dispatch problem," International Journal of Emerging Research in Management and Technology, vol. 6, no. 9, p. 112, 2018.

[21] M. Thirumeni and D. Thangavelusamy, "Design and analysis of hybrid PSO-GSA tuned PI and SMC controller for DC-DC Cuk converter," IET Circuits, Devices \& Systems, vol. 13, no. 3, pp. 374-384, 2019.

[22] M. Ahmad, W. Ali, H. Farooq, M. Jamil, M. Ali and A. U. Rehman, "Solving the problem of economic load dispatch for a small-scale power system using a novel hybrid PSO-GSA algorithm," 2018 International Symposium on Recent Advances in Electrical Engineering (RAEE), 2018, pp. 1-6.

[23] D. M. Mustafa, K. H. Youssef, I. F. Elarabawy and T. H. Abdelhamid, "Hybrid particle swarm optimization and gravitational search algorithm for BLDC motor speed control," 2018 Twentieth International Middle East Power Systems Conference (MEPCON), 2018, pp. 1140-1147.

[24] H. M. Hasanien and S. M. Muyeen, "Design optimization of controller parameters used in variable speed wind energy conversion system by genetic algorithms," IEEE Trans. Sustain. Energy, vol. 3, no.2, pp. 200-208, 2012. 